\title{
Effects of supplemental chromium propionate and rumen-protected amino acids on nutrient metabolism, neutrophil activation, and adipocyte size in dairy cows during peak lactation
}

\author{
K. Yuan, ${ }^{*}$ C. F. Vargas-Rodriguez, ${ }^{,}$L. K. Mamedova, ${ }^{*}$ M. B. Muckey, ${ }^{*}$ M. A. Vaughn, ${ }^{*}$ D. D. Burnett, ${ }^{*}$ \\ J. M. Gonzalez, ${ }^{*}$ E. C. Titgemeyer, ${ }^{*}$ K. E. Griswold,† and B. J. Bradford ${ }^{\star 1}$ \\ *Department of Animal Sciences and Industry, Kansas State University, Manhattan 66506 \\ †Kemin Industries, Des Moines, IA 50317
}

\section{ABSTRACT}

The objective of this study was to evaluate effects of chromium propionate $(\mathrm{CrPr})$, rumen-protected lysine and methionine (RPLM), or both on metabolism, neutrophil function, and adipocyte size in lactating dairy cows (38 $\pm 15 \mathrm{~d}$ in milk). Forty-eight individually fed Holstein cows (21 primiparous, 27 multiparous) were stratified by calving date in 12 blocks and randomly assigned to 1 of 4 treatments within block. Treatments were control, $\mathrm{CrPr}(8 \mathrm{mg} / \mathrm{d}$ of $\mathrm{Cr}$, KemTRACE brand chromium propionate $0.04 \%$, Kemin Industries Inc., Des Moines, IA), RPLM (10 g/d lysine and $5 \mathrm{~g} / \mathrm{d}$ methionine intestinally available, from LysiPEARL and MetiPEARL, Kemin Industries Inc.), or CrPr plus RPLM. Treatments were fed for $35 \mathrm{~d}$; blood plasma samples were collected on d 21 and 35 of treatment, and blood neutrophils were isolated from 24 cows for analysis of tumor necrosis factor $\alpha(T N F \alpha)$ and interleukin $1 \beta$ (IL$1 \beta$ ) transcript abundance in the basal state and after $12 \mathrm{~h}$ of lipopolysaccharide (LPS) activation. Tailhead subcutaneous adipose tissue samples were collected on d 35 for measurement of adipocyte size. Plasma glucose, nonesterified fatty acids, and glucagon concentrations were unaffected by treatments, whereas plasma insulin concentration was increased by RPLM. Basal $T N F \alpha$ transcript abundance in neutrophils was not affected by treatment, but basal $I L-1 \beta$ transcript abundance was decreased by RPLM and tended to be increased by $\mathrm{CrPr}$. After LPS activation, $\mathrm{CrPr}$ increased neutrophil $T N F \alpha$ transcript abundance. In addition, RPLM $\times$ parity interactions were detected for both $T N F \alpha$ and $I L-1 \beta$ abundance after LPS activation, reflecting enhanced responses in primiparous cows and attenuated responses in multiparous cows supplemented with RPLM. Adipocyte size was not affected by treatment. Supplemental CrPr and RPLM had minimal effects

Received November 26, 2013

Accepted February 15, 2014.

${ }^{1}$ Corresponding author: bbradfor@ksu.edu on metabolism when fed for $35 \mathrm{~d}$ near peak lactation but may modulate innate immune function in lactating dairy cows.

Key words: lysine, methionine, chromium, immunity

\section{INTRODUCTION}

Chromium is a nutrient that can influence animal metabolism. Supplementation of $\mathrm{Cr}$ in cattle has been shown to increase milk production (Hayirli et al., 2001; McNamara and Valdez, 2005; Smith et al., 2005), improve glucose clearance and insulin sensitivity (Bunting et al., 1994; Sumner et al., 2007; Spears et al., 2012), reduce lipolysis (Besong, 1996; Bryan et al., 2004), alter adipose tissue metabolism (McNamara and Valdez, 2005), and modulate immune response (Burton et al., 1993, 1996; Burton, 1995). Although considerable research has been conducted with $\mathrm{Cr}$ in cattle, $\mathrm{Cr}$ supplementation in cattle diets has only recently been permitted by the US Food and Drug Administration. Currently, Cr-propionate $(\mathbf{C r P r})$ is the only source of $\mathrm{Cr}$ allowed for supplementation to cattle in the United States, at inclusion rates up to $0.5 \mathrm{mg}$ of $\mathrm{Cr} / \mathrm{kg}$ of diet. By feeding $\mathrm{CrPr}$ to dairy cows from $21 \mathrm{~d}$ prepartum to 35 d postpartum, McNamara and Valdez (2005) increased DMI and milk yield in early lactation. Interestingly, they also observed that $\mathrm{CrPr}$ dramatically increased adipose tissue lipogenesis compared with that of controls in the postpartum period. Collectively, these results indicate that $\mathrm{CrPr}$ may improve production by modulating metabolism of lactating cows.

To improve the performance and productive efficiency of lactating cows, first-limiting AA such as rumen-protected lysine and methionine (RPLM) have been commonly supplemented (Chilliard and Doreau, 1997; Leonardi et al., 2003; Berthiaume et al., 2006). A recent meta-analysis (Patton, 2010) indicated that feeding rumen-protected methionine increased milk protein content and yield and slightly increased milk yield across 35 studies in the literature. However, little research has been conducted to determine effects of 
RPLM on glucose or lipid metabolism or immune function in dairy cows. Enhanced metabolic and immune function may contribute to improved milk production.

Currently, there are no reports regarding the interaction between $\mathrm{CrPr}$ and RPLM supplementation in dairy cows. We hypothesized that supplementation of both may generate effects superior to supplementing either one alone, in part because enhanced milk production in response to $\mathrm{CrPr}$ would increase essential AA requirements. Therefore, the objective of this study was to determine if $\mathrm{CrPr}$ and RPLM supplementation affects neutrophil function, adipocyte size, or intermediary nutrient metabolism in dairy cows near peak lactation.

\section{MATERIALS AND METHODS}

The Kansas State University Institutional Animal Care and Use Committee approved all experimental procedures. Production responses to these treatments are reported in a companion paper (Vargas-Rodriguez et al., 2014).

\section{Design and Treatments}

Forty-eight individually fed Holstein cows (21 primiparous, 27 multiparous, $38 \pm 15$ DIM, mean \pm SD) were stratified by calving date in 12 blocks and randomly assigned to 1 of 4 treatments within block. Treatments were control, $\mathrm{CrPr}(8 \mathrm{mg} / \mathrm{d}$ of $\mathrm{Cr}$ in the form of 20 $\mathrm{g} / \mathrm{d}$ KemTRACE chromium propionate $0.04 \%$; Kemin Industries Inc., Des Moines, IA), RPLM (10 g/d of lysine and $5 \mathrm{~g} / \mathrm{d}$ of methionine, intestinally available), or both $(\mathbf{C r P r}+\mathbf{R P L M})$. The RPLM supplement was composed of $48.8 \mathrm{~g} / \mathrm{d}$ of LysiPEARL and $15.3 \mathrm{~g} / \mathrm{d}$ of MetiPEARL (Kemin Industries Inc.). Treatments were premixed with ground corn and top-dressed at $200 \mathrm{~g} / \mathrm{d}$ for $35 \mathrm{~d}$. All cows were fed once daily $(1600 \mathrm{~h})$ for ad libitum intake of a diet formulated to meet NRC (2001) nutrient requirements (Table 1). Analysis by the Cornell Net Carbohydrate and Protein System version 6.1 (NDS version 3, Ruminant Management and Nutrition, Reggio Emilia, Italy) estimated metabolizable Met supply at $47 \mathrm{~g} / \mathrm{d}(2.03 \%$ of MP) and metabolizable Lys supply at $148 \mathrm{~g} / \mathrm{d}(6.38 \%$ of MP) with $22 \mathrm{~kg} / \mathrm{d}$ DMI in the control diet. The RPLM supplement was predicted to result in Lys and Met supplies of $6.77 \%$ and $2.23 \%$ of MP, respectively.

\section{Plasma Samples}

On d 21 and $35(1430 \mathrm{~h})$, approximately $14 \mathrm{~mL}$ of blood was collected from all cows from the coccygeal vessels into 2 evacuated tubes, one containing $\mathrm{K}_{3^{-}}$ EDTA (for analyses of NEFA, glucagon, insulin, leptin, and adiponectin) and the other containing potassium oxalate with sodium fluoride (for analysis of glucose) as a glycolytic inhibitor (Vacutainer, Becton Dickinson, Franklin Lakes, NJ). Samples were centrifuged at 2,000 $\times g$ for $15 \mathrm{~min}$ immediately after sample collection, and plasma was harvested and frozen at $-20^{\circ} \mathrm{C}$ until analysis. Plasma aliquots for glucagon analysis were added to tubes containing benzamidine (50 $\mathrm{m} M$ final concentration; Sigma-Aldrich Chemical Co., St. Louis, $\mathrm{MO})$ as a protease inhibitor. Plasma was analyzed for NEFA using an enzymatic colorimetric procedure (NEFA-HR, Wako Chemicals USA, Richmond, VA), glucose by a colorimetric kit (Autokit Glucose; Wako Chemicals USA), glucagon by a radioimmunoassay kit (\#GL-32K Millipore Corp., Billerica, MA), and insulin by a bovine-specific sandwich ELISA (\#10-1201-01, Mercodia AB, Uppsala, Sweden).

Plasma samples collected on d 35 were analyzed for leptin and adiponectin protein abundance by Western blot. Plasma samples $(1 \mu \mathrm{L})$ were diluted with $19 \mu \mathrm{L}$ of Laemmli sample buffer (Bio-Rad, Richmond, CA). The homogenate was heated at $90^{\circ} \mathrm{C}$ for $5 \mathrm{~min}$, cooled,

Table 1. Ingredient and nutritional composition of the basal diet

\begin{tabular}{lc}
\hline Item & Value \\
\hline Ingredient (\% of DM) & \\
Corn silage & 31.5 \\
Alfalfa hay & 23.4 \\
Wet corn gluten feed $^{1}$ & 6.8 \\
Ground corn & 23.1 \\
Whole cottonseed $_{\text {Mechanically extracted soybean meal }}^{2}$ & 4.6 \\
Solvent-extracted soybean meal & 2.1 \\
Ca salts of long-chain fatty acids & 5.1 \\
Micronutrient premix & 0.8 \\
Nutrient (\% of DM unless otherwise noted) & 2.6 \\
DM (\% as fed) & 57.9 \\
OM & 91.3 \\
CP & 16.7 \\
NDF & 31.7 \\
ADF & 20.1 \\
fNDF & 22.1 \\
NFC & 39.8 \\
Ether extract & 3.1 \\
Model-predicted $\mathrm{ME}^{6}(\mathrm{Mcal} / \mathrm{kg})$ & 2.50 \\
\hline
\end{tabular}

${ }^{1}$ SweetBran (Cargill Inc., Blair, NE).

${ }^{2}$ Soy Best (Grain States Soya, West Point, NE).

${ }^{3}$ Megalac-R (Church \& Dwight Co., Princeton, NJ).

${ }^{4}$ Premix consisted of $45.1 \%$ limestone, $32.2 \%$ sodium bicarbonate, $6.4 \%$ magnesium oxide, $5.2 \%$ sodium chloride, $5.2 \%$ vitamin $\mathrm{E}$ pre$\operatorname{mix}(44 \mathrm{IU} / \mathrm{g}), 0.45 \%$ vitamin A premix $(30 \mathrm{kIU} / \mathrm{g}), 0.19 \%$ vitamin D premix (30 kIU/g), 2.1\% 4-Plex (Zinpro Corp., Eden Prairie, MN; contains $2.58 \% \mathrm{Zn}, 1.48 \% \mathrm{Mn}, 0.90 \% \mathrm{Cu}, 0.18 \% \mathrm{Co}, 8.21 \%$ Met, and $3.80 \%$ Lys), $0.96 \%$ selenium premix (600 mg/kg Se), $0.45 \%$ Zinpro 100 (Zinpro Corp.; contains $10 \% \mathrm{Zn}$ and $20 \%$ Met), $0.03 \%$ ethylenediamine dihydriodide premix (3.65\% I), 0.88\% Kallsil (Kemin Industries Inc., Des Moines, IA), and 0.88\% Myco CURB (Kemin Industries Inc.).

${ }^{5}$ Forage NDF.

${ }^{6} \mathrm{ME}$ predicted by CNCPS 6.1 (NDS version 3, Ruminant Management \& Nutrition, Reggio Emilia, Italy). 
and loaded onto a 4 to $20 \%$ Tris- $\mathrm{HCl}$ gel for electrophoresis. Samples were separated by SDS-PAGE and dry-transferred onto nitrocellulose membranes (iBlot, Invitrogen, Carlsbad, CA). Membranes were blocked for $2 \mathrm{~h}$ in blocking buffer $(5 \%$ dry milk in Tris- $\mathrm{HCl}$ buffer, pH 7.5, with $0.05 \%$ Tween 20). After incubation with blocking buffer, the membranes were washed 3 times for 5 min each with washing buffer (PBS, pH 7.5, containing $0.05 \%$ Tween 20). Membranes were then incubated with primary antibodies (1:500) against leptin (sc-8325, Santa Cruz Biotechnology Inc., Santa Cruz, CA) and adiponectin (A6354, Sigma-Aldrich Co.) overnight at $4^{\circ} \mathrm{C}$. After washing, a secondary antibody (sc2313, Santa Cruz Biotechnology) diluted 1:10,000 was incubated for $1 \mathrm{~h}$ at room temperature. Immunodetection was performed by chemiluminescence (West-Dura; Thermo Scientific, Waltham, MA) and bands quantified by scanning densitometry (ChemiDoc-It Imaging System; UVP Inc., Upland, CA).

\section{Neutrophil Isolation}

On d 21 and $35(0700 \mathrm{~h}), 50 \mathrm{~mL}$ of blood was obtained by jugular venipuncture from 6 blocks of the cows for isolation of neutrophils. Blood was collected in $50-\mathrm{mL}$ tubes (Becton Dickinson) with $0.75 \mathrm{~mL}$ of heparin (1,000 units/mL, Acros Organics Inc., Fair Lawn, NJ). Blood was placed on ice for transport to the laboratory $(<60 \mathrm{~min})$ and then $20 \mathrm{~mL}$ of whole blood was combined with $20 \mathrm{~mL}$ of Ficoll-Paque PLUS (GE Healthcare, Pittsburgh, PA) and centrifuged at $800 \times g$ for $50 \mathrm{~min}$ at $4^{\circ} \mathrm{C}$. Centrifugation separated the blood into 6 distinct bands: plasma, monocytes, isolation medium, neutrophils, more isolation medium, and the red blood cell pellet. The top 3 layers (plasma, monocytes, and isolation medium) were removed, and neutrophils were collected and washed 3 times with $\mathrm{Ca}^{2+}$ - and $\mathrm{Mg}^{2+}$-free Hanks' balanced salt solution (Sigma-Aldrich Chemical Co.). Isolated neutrophils from each cow were split into 2 samples, one of which was immediately frozen for subsequent analysis of basal neutrophil status. The remaining neutrophils were suspended in Dulbecco's modified Eagle medium with 10\% fetal bovine serum and 1\% penicillin-streptomycin (Sigma-Aldrich Chemical Co.) and incubated with $1 \mu \mathrm{g} /$ mL LPS (from Escherichia coli O55:B5, Sigma-Aldrich Chemical Co.) for $12 \mathrm{~h}$. Cells were frozen at $-80^{\circ} \mathrm{C}$ until analysis of transcript abundance of tumor necrosis factor $\alpha(T N F \alpha)$ and IL-1 $\beta(I L-1 \beta)$ in the basal state or after $12 \mathrm{~h}$ of LPS activation.

\section{Transcript Abundance}

Total RNA was extracted from neutrophils using a commercial kit (RNeasy Lipid Tissue Mini Kit, Qiagen
Inc., Valencia, CA) according to the manufacturer's instructions. Two micrograms of total RNA was used as template for the reverse transcriptase reaction using random primers (High-Capacity cDNA RT Kit, Applied Biosystems, Foster City, CA). Quantitative real-time PCR was performed in duplicate on 96-well plates with $1 / 20$ of the cDNA product in the presence of $200 \mathrm{nmol} / \mathrm{L}$ gene-specific forward and reverse primers with real-time SYBR green fluorescent detection using SYBR Green Premix reagent (7500 Fast RealTime PCR System, Applied Biosystems). Primers were designed (http://www.ncbi.nlm.nih.gov/tools/primerblast) using the following GenBank accession numbers to generate these primer sequences (all $\left.5^{\prime}-3^{\prime}\right): T N F \alpha$ (NM_173966.3), forward AAGTAACAAGCCGGTAGCCCA, reverse CTTCCAGCTTCACACCGTTG; IL-1 $\beta$ (NM_174093.1), forward CACGTGGGCTGAATAACCCCGA, reverse AGGCAGTCGGGCATGGATCAGA; ribosomal protein subunit 9 (RPS9) (NM_001101152.2), forward GAACAAACGTGAGGTCTGGAGG, reverse TTACCTTCGAACAGACGCCG. All sample values were normalized against RPS9 (Mamedova et al., 2010), and relative gene expression was quantified by using the $2^{-\Delta \mathrm{Ct}}$ method. Efficiencies of PCR reactions, determined by serial dilution of pooled samples, were as follows: $T N F \alpha, 93 \%$; $I L-1 \beta, 80 \%$; and RPS9, $87 \%$.

\section{Adipose Tissue Biopsy}

On d 35, tailhead subcutaneous adipose tissue samples were collected from all cows. At the time of sampling, the site was shaved and aseptically prepared. The tailhead was then anesthetized with $2 \mathrm{~mL}$ of $2 \%$ lidocaine hydrochloride. An incision of 2 to $3 \mathrm{~cm}$ in length was made between the tailhead and the tuber ischii, and adipose tissue was collected as described previously (Smith and McNamara, 1990). Incisions were closed by a skin stapler (Oasis Disposable Skin Stapler, Med-Vet International, Mettawa, IL). Tissue samples were trimmed to eliminate contaminating tissue and were cut into small pieces (approximately $1 \mathrm{~cm}^{3}$ ). One sample from each cow was embedded in Optimal Cutting Temperature compound (OCT, Tissue-Tek, Sakura Finetek, Torrance, CA) and frozen at $-80^{\circ} \mathrm{C}$ for subsequent analysis of adipocyte size.

\section{Adipocyte Morphology}

Adipose tissue cryosections $(14 \mu \mathrm{m})$ were prepared on a cryostat (Microm HM550, Thermo Fisher Scientific Inc., Kalamazoo, MI) and mounted on SuperFrost slides (Thermo Fisher Scientific Inc.). Tissue sections were fixed in $4 \%$ paraformaldehyde for $10 \mathrm{~min}$, rinsed 
twice with PBS, and covered with a coverslip. Representative images were captured using a Nikon Eclipse TI-U inverted microscope with $10 \times$ working distance magnification (Nikon Instruments Inc., Melville, NY). Five representative photomicrographs per animal were captured using a Nikon DS-QiMc digital camera (Nikon Instruments Inc.). All the adipocytes in each photomicrograph and at least 150 adipocytes per sample were analyzed for adipocyte cross-sectional area using NISElements Imaging Software (Basic Research, 3.3; Nikon Instruments Inc.).

\section{Calculations and Statistical Analysis}

An insulin sensitivity measure, revised quantitative insulin sensitivity check index (RQUICKI) was calculated as (Holtenius and Holtenius, 2007): RQUICKI $=1 /\left[\log \left(\mathrm{G}_{\mathrm{b}}\right)+\log \left(\mathrm{I}_{\mathrm{b}}\right)+\log \left(\mathrm{NEFA}_{\mathrm{b}}\right)\right]$, where $\mathrm{G}_{\mathrm{b}}=$ glucose $(\mathrm{mg} / \mathrm{dL}), \mathrm{I}_{\mathrm{b}}=$ insulin $(\mu \mathrm{U} / \mathrm{mL})$, and $\mathrm{NEFA}_{\mathrm{b}}$ $=$ NEFA $(\mathrm{mmol} / \mathrm{L})$, such that a lower RQUICKI indicates greater insulin resistance. Insulin, determined in nanograms per milliliter, was converted to micro-units per milliliter by assuming an activity of $25.1 \mu \mathrm{U} / \mathrm{ng}$ (JAMA, 2010). The distribution of adipocyte area values within each cow (from 5 randomly selected cows) was plotted to assess the normality of the population. In contrast to some previous reports demonstrating bimodal adipocyte populations in relatively obese animals (Cruz et al., 2012), adipocyte populations within animal were unimodal in this study. However, distributions were right-skewed because of small numbers of very large adipocytes. Therefore, median adipocyte area from each cow was used instead of the mean value for further analysis.

One cow receiving $\mathrm{CrPr}+\mathrm{RPLM}$ developed severe mastitis on d 20 of treatment and was subsequently removed from the study; no data were collected or analyzed for this cow. Data were analyzed using Proc MIXED of SAS (version 9.2; SAS Institute Inc., Cary, $\mathrm{NC}$ ) to assess the fixed effects of day, CrPr, RPLM, parity, and all interactions, and the random effect of block. With the exception of $\mathrm{CrPr} \times \mathrm{RPLM}$, interactions were removed from models when $P>0.30$. Data for $T N F \alpha$ and $I L-1 \beta$ transcript abundance in neutrophils were log-transformed for analysis and reported values are back-transformed. Repeated measures over time within cow were modeled with an autoregressive $[\mathrm{AR}(1)]$ covariance structure. Denominator degrees of freedom were estimated using the Kenward-Rogers method. Values were deemed outliers and omitted from analysis when Studentized residuals were $>3.5$ or $<-3.5$. Significance was declared at $P \leq 0.05$ and trends at $0.05<P \leq$ 0.10 . Treatment means were separated with pair-wise $t$-tests when interactions were significant.

\section{RESULTS}

\section{Plasma Data}

Plasma metabolite and hormone concentrations are shown in Table 2. Glucose and NEFA concentrations were not affected $(P>0.10)$ by RPLM or $\mathrm{CrPr}$. Compared with values on $\mathrm{d} 21$, glucose tended to be decreased (50.5 vs. $53.1 \pm 1.5 \mathrm{mg} / \mathrm{dL}, P=0.10)$ and NEFA was decreased (223 vs. $342 \pm 22 \mu M, P<0.001$ ) on d 35. Insulin was unaffected $(P>0.10)$ by $\mathrm{CrPr}$, but was increased $(P=0.03)$ by RPLM and was greater on d 35 than on d 21 (311 vs. $259 \pm 23 \mathrm{pg} / \mathrm{mL}, P=0.04$ ). Although glucagon was not affected $(P>0.10)$ by $\mathrm{CrPr}$ or RPLM, we detected an interaction of RPLM $\times$ day $(P=0.04)$, reflecting increased $(P=0.05)$ glucagon concentration (173 v. $159 \pm 5.6 \mathrm{pg} / \mathrm{mL}$ ) by RPLM on d 35; no difference $(P=0.53)$ was detected on d 21 . The RQUICKI measure of insulin sensitivity did not show treatment effects $(P>0.10)$ but tended to be increased on d 35 compared with d 21 (0.569 vs. 0.536 $\pm 0.014, P=0.08)$. Primiparous cows tended to have lesser RQUICKI values than multiparous cows (0.536 vs. $0.570 \pm 0.014, P=0.07$ ).

Plasma leptin and adiponectin protein abundance on d 35 is shown in Figure 1. Plasma leptin protein abundance (Figure 1A) tended to be increased $(P=0.09)$ by RPLM, but was unaffected $(P>0.10)$ by $\mathrm{CrPr}$. In addition, we observed a tendency for a $\mathrm{CrPr} \times$ parity interaction $(P=0.08)$, reflecting decreased $(P=0.04)$ leptin abundance by $\mathrm{CrPr}$ in multiparous cows but not $(P=0.53)$ in primiparous cows (Figure 1B). Plasma adiponectin protein abundance (Figure 1C) was not altered $(P>0.10)$ by treatments.

\section{Neutrophil Transcript Abundance}

Basal TNF $\alpha$ transcript abundance (Figure 2A) in neutrophils was not affected $(P>0.10)$ by treatment or day. After LPS activation, $T N F \alpha$ transcript abundance increased compared with nonstimulated controls and tended $(P=0.07)$ to be greater in cells collected on d 21 compared with those collected on d 35. Dietary CrPr increased $(P=0.02) T N F \alpha$ abundance in LPSactivated neutrophils (Figure $2 \mathrm{~B}$ ). We observed an $\mathrm{RPLM} \times$ parity interaction $(P<0.01)$, reflecting increased $T N F \alpha$ transcript abundance in LPS-stimulated neutrophils from primiparous cows $(P<0.01)$ and a tendency for decreased $T N F \alpha$ in multiparous cows $(P$ $=0.07$ ) in response to RPLM (Figure $2 \mathrm{C}$ ).

Basal $I L-1 \beta$ transcript abundance in neutrophils was decreased $(P=0.05)$ by RPLM, and tended to be increased by $\operatorname{CrPr}(P=0.08$, Figure $3 \mathrm{~A})$. Basal $I L-1 \beta$ transcript abundance was increased between $\mathrm{d}$ 
Table 2. Effects of chromium propionate ( $\mathrm{CrPr}$ ) and rumen-protected lysine and methionine (RPLM) on plasma metabolites and hormones in lactating dairy cows on $\mathrm{d} 21$ and 35 of dietary treatment ${ }^{1}$

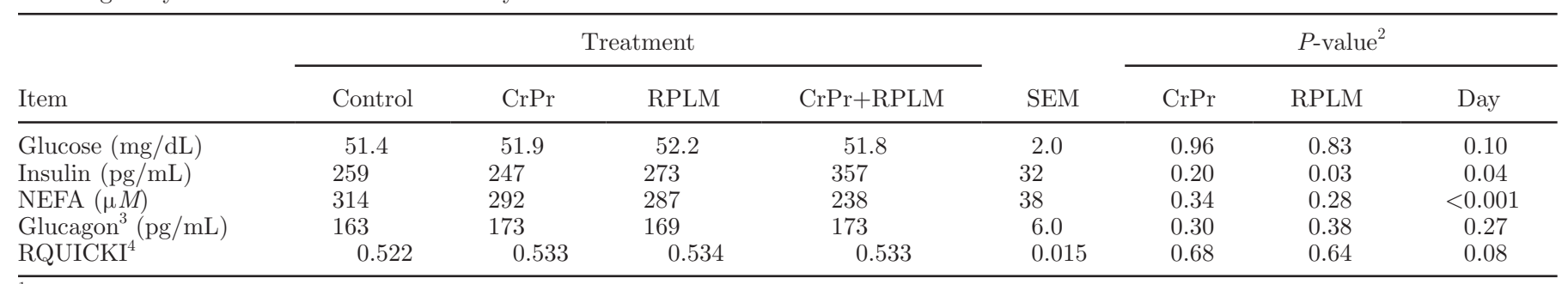

${ }^{1}$ Values are least squares means across d 21 and 35

${ }^{2}$ No interactions were significant except as noted for glucagon.

${ }^{3} \mathrm{RPLM} \times$ day interaction $(P=0.04)$. Glucagon concentration was increased by RPLM on d $35(0.173 \mathrm{vs} .0 .159 \pm 0.006 \mathrm{ng} / \mathrm{mL}, P=0.05)$, but not on d 21 (0.169 vs. $0.173 \pm 0.006 \mathrm{ng} / \mathrm{mL}, P=0.53)$.

${ }^{4}$ Revised quantitative insulin sensitivity check index (Holtenius and Holtenius, 2007).

21 and $\mathrm{d} 35(P=0.01)$ and was greater $(P=0.04)$ in primiparous cows than multiparous cows $(12.2 \pm 6.3$ vs. $2.7 \pm 1.2$ arbitrary units). After LPS activation, $I L-1 \beta$ transcript abundance increased dramatically, but no treatment or day effects $(P>0.10)$ were observed (Figure 3B). However, we detected a RPLM $\times$ parity interaction $(P<0.01)$, reflecting increased $I L-1 \beta$ transcript abundance in primiparous cows $(P=0.03)$ and decreased $I L-1 \beta$ in multiparous cows $(P=0.01)$ in response to RPLM (Figure 3C).

\section{Adipocyte Morphology}

Figure $4 \mathrm{~A}$ depicts a representative photomicrograph of an adipose tissue cross-section. Tailhead subcutaneous adipocyte cross-sectional area was not affected $(P$ $>0.10$ ) by RPLM or $\mathrm{CrPr}$ (Figure 4B), but was greater $(P=0.02)$ in primiparous compared with multiparous cows $\left(4,942\right.$ vs. $\left.3,577 \pm 427 \mu \mathrm{m}^{2}\right)$. Median adipocyte cross-sectional area was positively correlated with d 35 BCS $(P<0.001$, Figure 5$)$, but not BW $(P>0.10)$.

\section{DISCUSSION}

In this study, CrPr supplementation did not affect plasma glucose, NEFA, insulin, or glucagon concentrations in lactating cows. Most studies evaluating the effects of $\mathrm{Cr}$ supplementation on dairy cattle metabolism have been conducted in the periparturient period, and effects on circulating hormones and metabolites in lactating animals have been limited. Hayirli et al. (2001) reported that supplementing periparturient cows with $0,0.03,0.06$, and $0.12 \mathrm{mg} / \mathrm{kg}$ of $\mathrm{BW}^{0.75}$ of $\mathrm{Cr}$ as chromium-L-methionine (Cr-Met) decreased plasma insulin but did not affect plasma glucose, glucagon, or NEFA concentrations in early lactation. Smith et al. (2008) reported that supplementation of 0.03 or 0.06 $\mathrm{mg} / \mathrm{kg} \mathrm{BW} \mathrm{B}^{0.75}$ of $\mathrm{Cr}$ as Cr-Met had no effects on these plasma concentrations in early lactation despite some alterations in late gestation. Interestingly, we found that RPLM supplementation increased plasma insulin concentration. Essential AA have long been considered to be physiologic stimuli for insulin secretion in humans (Floyd et al., 1966), but few studies have focused on the influence of dietary AA supplementation on insulin concentrations in dairy cows. By feeding a rumen-protected methionine product, Blum et al. (1999) observed increased plasma insulin concentrations in lactating cows within $5 \mathrm{~d}$ of supplementation. In the present study, although insulin was significantly increased by RPLM, this increase was not likely of great consequence for the metabolism and performance of animals because other metabolites were unaffected.

One important characteristic of $\mathrm{Cr}$ is its modulatory effect on insulin sensitivity. It has been established that $\mathrm{Cr}$ supplementation alleviates insulin resistance, enhances glucose tolerance, and improves metabolism in obese or type 2 diabetic subjects (Cefalu et al., 2010; Wang and Cefalu, 2010; Kim et al., 2011). Although the mode of action is not precisely known, Cr has been shown to enhance insulin binding, insulin receptor abundance, and pancreatic $\beta$-cell sensitivity (Wang and Cefalu, 2010). A recent paper also proposed that $\mathrm{Cr}$ improves insulin action by activating glucose transporter-4 trafficking and enhancing insulin-stimulated glucose transport in adipocytes (Chen et al., 2006). In the bovine, Sumner et al. (2007) reported that CrPr supplementation improved glucose tolerance in growing Holstein heifers. There has also been interest in the effects of Cr supplementation on insulin sensitivity in the periparturient period (Sano et al., 1993), when insulin resistance typically occurs (Bell and Bauman, 1997). Subiyatno et al. (1996) found that supplementation of $0.5 \mathrm{mg}$ of $\mathrm{Cr} / \mathrm{kg}$ of DM beginning at 6 wk prepartum increased insulin sensitivity in primiparous but not multiparous dairy cows at 2 wk before parturition. Hayirli et al. (2001) reported that Cr-Met supplementation from $21 \mathrm{~d}$ prepartum to $28 \mathrm{~d}$ postpartum improved glu- 

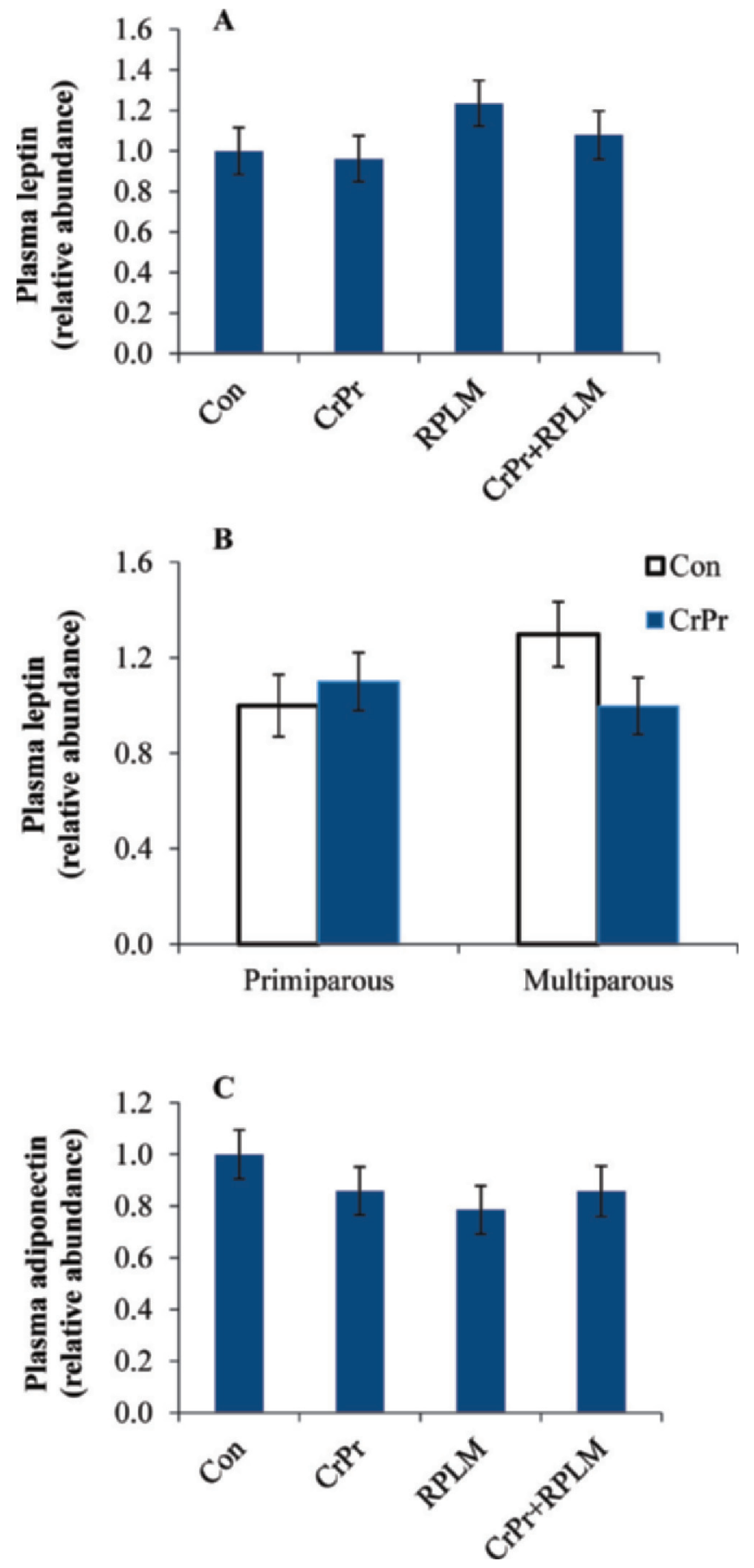

Figure 1. Plasma leptin and adiponectin protein abundance in lactating dairy cows supplemented with control (Con), chromium propionate $(\mathrm{CrPr})$, rumen-protected lysine and methionine (RPLM), or both $(\mathrm{CrPr}+\mathrm{RPLM})$. Plasma samples were collected on d 35 of dietary treatment, and protein abundance was measured by Western blot. (A) We observed a tendency for increased leptin abundance in response to RPLM $(P=0.09)$ but no effects of $\operatorname{CrPr}(P=0.33)$ or RPLM $\times \mathrm{CrPr}$ $(P=0.56)$. (B) We observed a tendency for a $\mathrm{CrPr} \times$ parity interaction $(P=0.08)$, reflecting decreased $(P=0.04)$ leptin abundance by $\mathrm{CrPr}$ in multiparous cows, but not in primiparous cows $(P=0.53)$. (C) Relative abundance of adiponectin was not affected by RPLM $(P$ $=0.18), \mathrm{CrPr}(P=0.66)$, or RPLM $\times \operatorname{CrPr}(P=0.19)$. Error bars are $\mathrm{SEM} ; \mathrm{n}=12$. Color version available in the online PDF. cose tolerance and insulin responsiveness measured at $28 \mathrm{~d}$ postpartum in multiparous dairy cows. Therefore, by modulating insulin action, $\mathrm{Cr}$ may have significant implications for health and performance of lactating dairy cows. In the current study, we used RQUICKI to estimate insulin sensitivity (Holtenius and Holtenius, 2007). We found that RQUICKI tended to be lesser on d 21 compared with d 35, which is consistent with insulin resistance in early lactation. Furthermore, RQUICKI tended to be lesser in primiparous compared with multiparous cows, indicating that, in this study, first-lactation heifers were relatively more insulin resistant. However, RQUICKI was not affected by treatments, suggesting that $\mathrm{CrPr}$ and RPLM did not alter insulin sensitivity.

Neutrophils are the first line of immune defense in dairy cows. Upon maturation, neutrophils are released into circulation and play key roles for immune surveillance and defense against pathogens (Burton and Erskine, 2003). Impaired neutrophil trafficking, phagocytosis, and killing directly contribute to immunosuppression and increased disease incidence in early-lactation cows (Kehrli et al., 1989). Among other functions, neutrophils serve as a significant source of proinflammatory cytokines, such as TNF $\alpha$ and IL-1 $\beta$ (Sohn et al., 2007). These cytokines are critical in activating and coordinating immune responses. As a cell wall component of gram-negative bacteria, LPS has frequently been used to stimulate immune cells; the capacity of these activated cells to produce proinflammatory cytokines can be used to assess the competence of these immune cells (Mani et al., 2012).

In this study, we evaluated the effect of $\mathrm{CrPr}$ and RPLM supplementation on neutrophil function by determining $T N F \alpha$ and $I L-1 \beta$ transcript abundance in neutrophils in the basal state and after $12 \mathrm{~h}$ of LPS activation. We found that $\mathrm{CrPr}$ did not affect basal $T N F \alpha$ transcript abundance but significantly increased its abundance after LPS activation. These results suggest that $\mathrm{CrPr}$ supplementation may improve innate immune response upon activation. Several studies have highlighted the role of $\mathrm{Cr}$ in bovine immunity. Burton et al. (1993) reported that $\mathrm{Cr}$ supplementation at 0.5 $\mathrm{mg}$ of $\mathrm{Cr} / \mathrm{kg}$ of DM from 6 wk prepartum through 16 wk postpartum increased antibody responses to ovalbumin administration and mitogen-stimulated blastogenesis of blood monocytes in lactating cows. In addition, TNF $\alpha$ and IL-2 production from mitogen-stimulated monocytes was significantly decreased for cows supplemented with $\mathrm{Cr}$ compared with controls, particularly around peak lactation (Burton et al., 1996).

Interestingly, RPLM increased LPS responsiveness of neutrophils from primiparous cows but decreased responsiveness of neutrophils from multiparous cows, 
based on both $T N F \alpha$ and $I L-1 \beta$ results. The reasons underlying the discrepant responses to RPLM supplementation in primiparous and multiparous cows are unclear. We also observed that basal $I L-1 \beta$ transcript abundance in neutrophils was decreased by RPLM and tended to be increased by $\mathrm{CrPr}$. Recent research has suggested that AA play an important role in immune modulation by regulating immune cell activation, proliferation, antibody production, and cytokine production, whereas dietary AA deficiency directly impairs immune function of animals ( $\mathrm{Li}$ et al., 2007). For example, lysine deficiency limits cytokine synthesis and lymphocyte proliferation, and impairs immune responses in chickens (Konashi et al., 2000). Methionine supplementation markedly enhanced several key aspects of innate and humoral immune responses in chickens infected with virus (Li et al., 2007). Although little research has directly assessed the effects of these AA on bovine inflammation and immune function, the interaction between these nutrients and immunity warrants further research.

Several studies have been conducted in an attempt to modulate lipolysis in lactating dairy cows by dietary manipulations (Baumgard et al., 2002; McNamara and Valdez, 2005; Yuan et al., 2012). For example, CLA (trans-10,cis-12 isomer) decreased milk fat synthesis in lactating cows and reduced body fat accretion in growing animals by decreasing de novo lipogenesis (Bauman et al., 2000). Recently, Akter et al. (2011) reported that supplementation of dairy cows with $100 \mathrm{~g}$ of CLA/d (about $6 \%$ each of cis-9,trans-11 and trans-10,cis-12 isomers) for the first $100 \mathrm{~d}$ of lactation considerably decreased adipocyte sizes in different fat depots. This finding supports the concept that adipocyte size is sensitive to altered rates of lipogenesis or lipolysis in dairy cows (McNamara, 1991). By feeding $10 \mathrm{mg} / \mathrm{d}$ of $\mathrm{Cr}$ as $\mathrm{CrPr}$ to dairy cows from $21 \mathrm{~d}$ prepartum to 35 d postpartum, McNamara and Valdez (2005) dramatically increased adipose tissue lipogenesis postpartum but did not affect rates of lipolysis. In the present study, however, we did not detect effects of $\mathrm{CrPr}$ or RPLM on subcutaneous adipocyte size. Interestingly, adipocyte size was positively correlated with BCS, supporting the observation that fatter cows typically have greater adipocyte size (McNamara, 1991). In addition, we found that adipocyte size was greater in primiparous than multiparous cows, which is consistent with the observation that primiparous cows tended to have greater BCS than multiparous cows (2.94 vs. $2.70 \pm$ $0.085, P=0.07)$.

We also measured the plasma protein abundance of several key hormones secreted from adipocytes to assess adipose tissue endocrine status. Leptin is primarily secreted by adipocytes and plays a central role in the
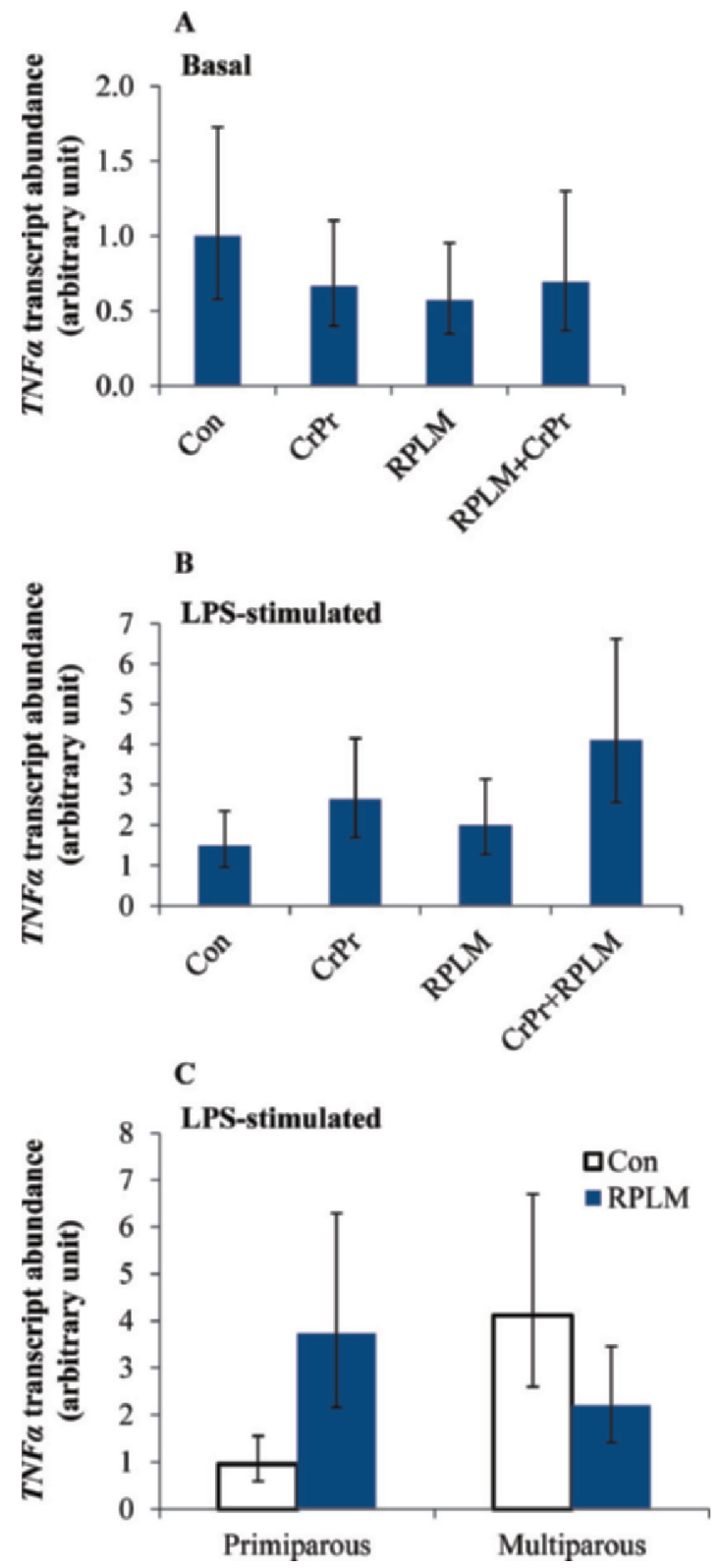

Figure 2. Neutrophil transcript abundance of tumor necrosis factor $\alpha(T N F \alpha)$ in the basal state or after $12 \mathrm{~h}$ of LPS $(1 \mu \mathrm{g} / \mathrm{mL})$ activation. Cows were supplemented with control (Con), chromium propionate $(\mathrm{CrPr})$, rumen-protected lysine and methionine (RPLM), or both ( $\mathrm{CrPr}+\mathrm{RPLM})$. Neutrophils were isolated from blood samples collected on d 21 and 35 of dietary treatments. (A) Basal $T N F \alpha$ abundance was not affected by RPLM $(P=0.59), \operatorname{CrPr}(P=0.82)$, or $\mathrm{RPLM} \times \mathrm{CrPr}(P=0.53)$. We observed a tendency for a $\mathrm{CrPr}$ $\times$ day interaction $(P=0.09)$, but $\mathrm{CrPr}$ did not affect $(P>0.10)$ $T N F \alpha$ transcript abundance on either d 21 or 35 (data not shown); (B) LPS-activated $T N F \alpha$ transcript abundance was increased $(P=$ $0.02)$ by $\mathrm{CrPr}$ supplementation but no effects were detected for RPLM $(P=0.14)$ or RPLM $\times \operatorname{CrPr}(P=0.76) ; T N F \alpha$ transcript abundance tended to be greater $(P=0.07)$ on d 21 compared with d 35 (data not shown); (C) LPS-activated $T N F \alpha$ transcript abundance was affected by an RPLM $\times$ parity interaction $(P<0.01)$, reflecting increased TNF $\alpha$ transcript abundance in primiparous cows $(P<0.01)$ and a tendency for decreased $T N F \alpha$ transcript abundance in multiparous cows $(P=0.07)$ in response to RPLM. Error bars are SEM; $\mathrm{n}=6$. Color version available in the online PDF. 
A

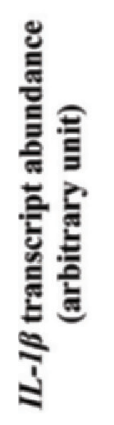

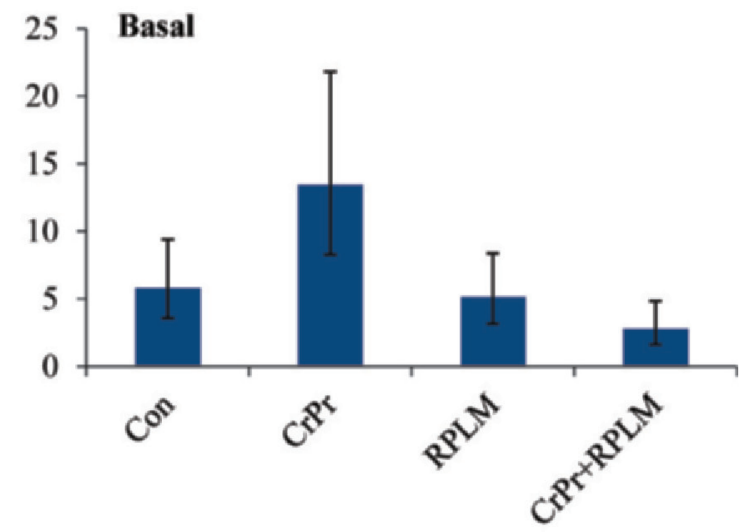

B

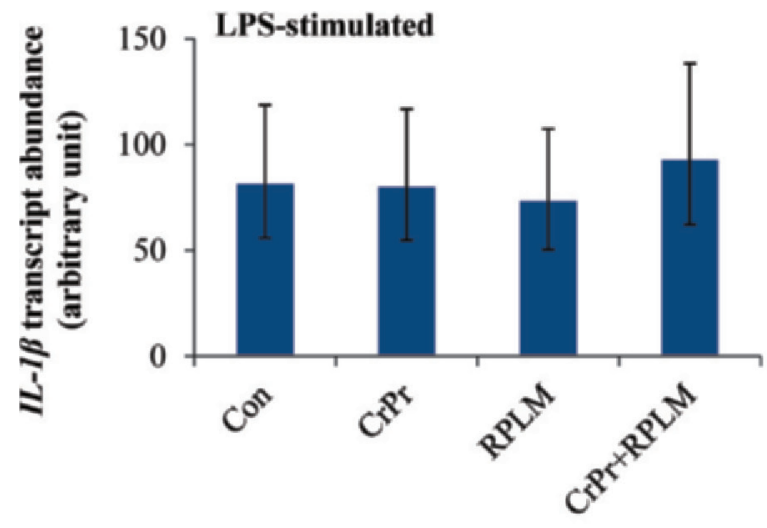

C

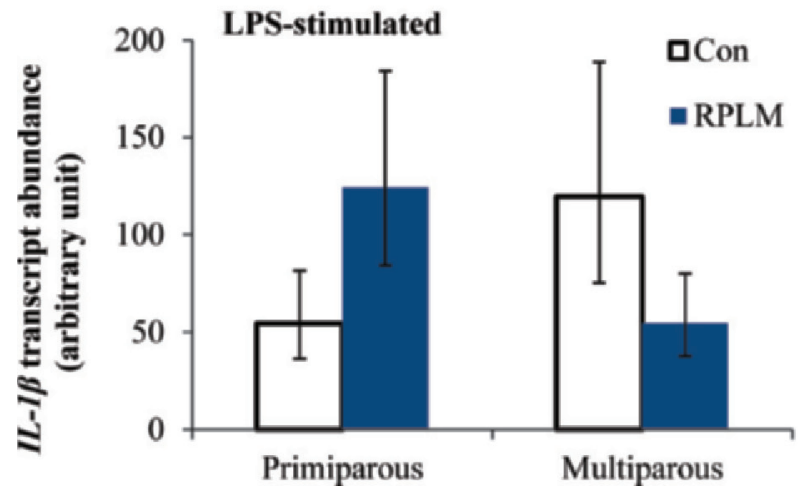

Figure 3. Neutrophil transcript abundance of IL-1 $(I L-1 \beta)$ in the basal state or after $12 \mathrm{~h}$ of LPS $(1 \mu \mathrm{g} / \mathrm{mL})$ activation. Cows were supplemented with control (Con), chromium propionate $(\mathrm{CrPr})$, rumenprotected lysine and methionine (RPLM), or both (CrPr+RPLM). Neutrophils were isolated from blood samples collected on d 21 and 35 of dietary treatments. (A) Basal $I L-1 \beta$ transcript abundance was decreased $(P=0.05)$ by RPLM, and tended to be increased $(P=$ $0.08)$ by $\mathrm{CrPr}$, but we detected no RPLM $\times \mathrm{CrPr}$ interaction $(P=$ $0.13)$; (B) LPS-activated $I L-1 \beta$ transcript abundance was not affected by $\operatorname{RPLM}(P=0.91), \operatorname{CrPr}(P=0.60)$, or $\operatorname{RPLM} \times \operatorname{CrPr}(P=$ $0.54) ;(C)$ LPS-activated $I L-1 \beta$ transcript abundance was affected by a RPLM $\times$ parity interaction $(P<0.01)$, reflecting increased $I L-1 \beta$ transcript abundance in primiparous cows $(P=0.03)$ and decreased $I L-1 \beta$ transcript abundance in multiparous cows $(P=0.01)$ in response to RPLM. Error bars are SEM; $\mathrm{n}=6$. Color version available in the online PDF.
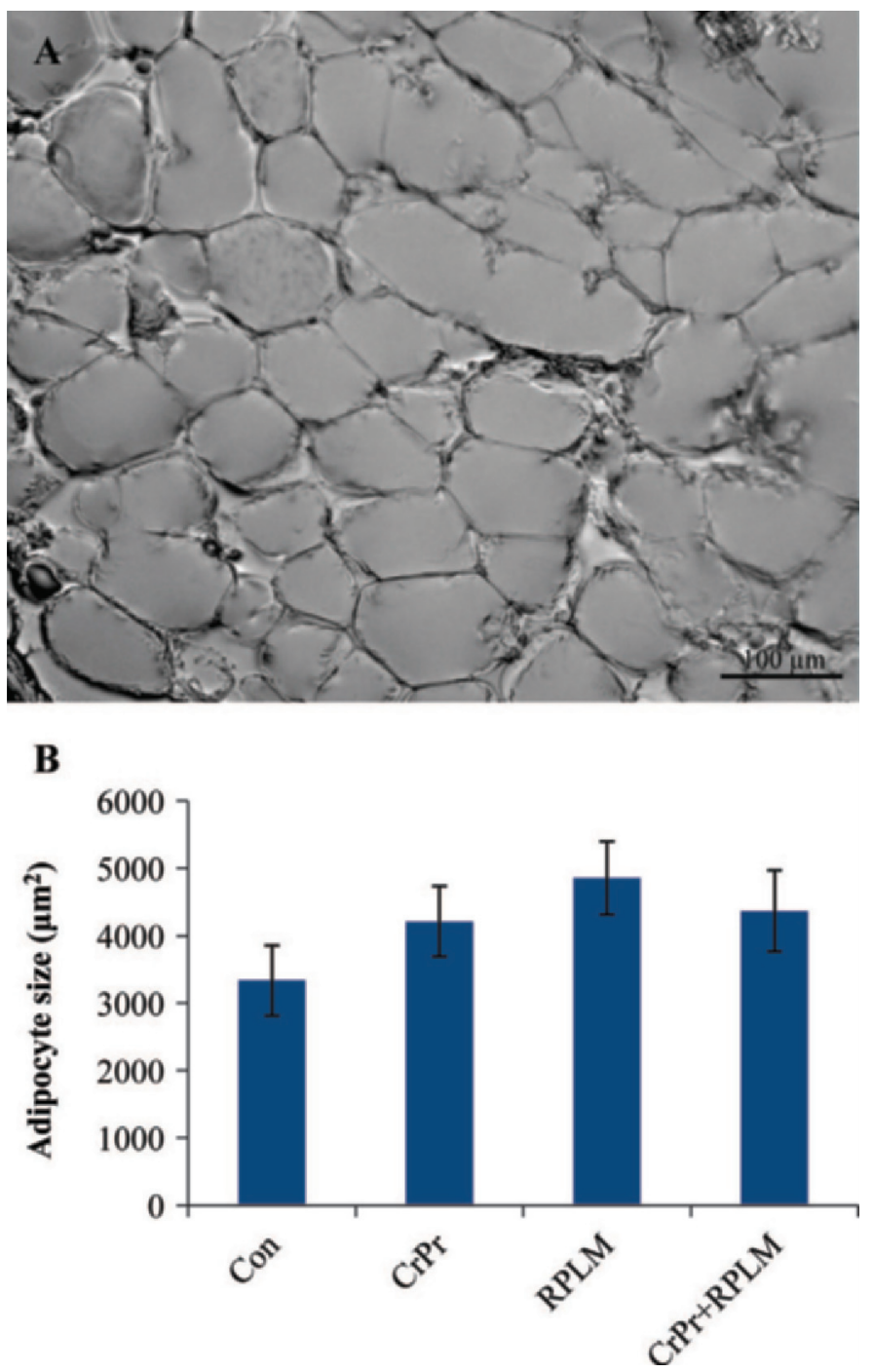

Figure 4. Subcutaneous adipocyte size in lactating dairy cows. Cows were supplemented with control (Con), chromium propionate $(\mathrm{CrPr})$, rumen-protected lysine and methionine (RPLM), or both (CrPr+RPLM). Adipose tissue samples were collected from the tailhead on d 35 of dietary treatment for assessment of median $(\geq 150$ cells/cow) cross-sectional area of adipocytes. (A) Representative photomicrograph (original magnification $10 \times$ ) of adipose tissue section. Scale bar $=100 \mu \mathrm{m}$. (B) There were no effects of RPLM $(P=0.14)$, $\mathrm{CrPr}(P=0.58)$, or RPLM $\times \operatorname{CrPr}(P=0.46)$ on adipocyte size. Color version available in the online $\mathrm{PDF}$.

regulation of feed intake, energy metabolism, and body condition (Ingvartsen and Boisclair, 2001; Block et al., 2003). In dairy cows, plasma leptin concentrations have been shown to be positively related to body fatness (Reist et al., 2003; Kokkonen et al., 2005). In this study, however, plasma leptin protein abundance was not correlated with BCS $\left(P=0.53, \mathrm{R}^{2}=0.009\right.$, data not shown). Leptin abundance tended to be increased by RPLM, and was decreased by $\mathrm{CrPr}$ in multiparous cows. Adiponectin, another adipokine secreted by adi- 


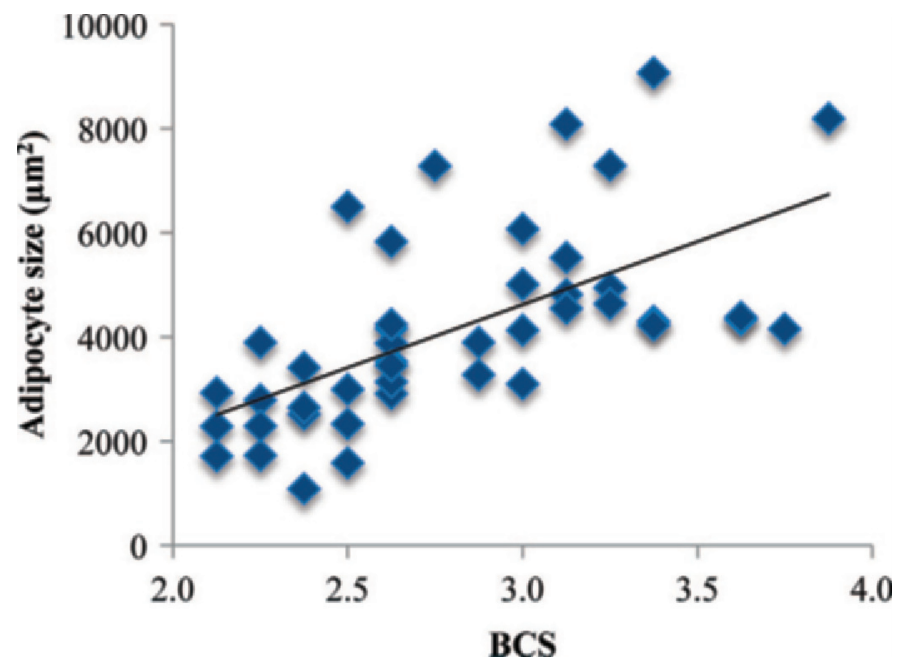

Figure 5. Correlation between median cross-sectional area of subcutaneous adipocytes and BCS (on d 35) in lactating dairy cows. Adipose tissue samples were collected on d 35 of dietary treatment Adipocyte sizes were positively correlated with BCS $\left(P<0.001, \mathrm{R}^{2}=\right.$ 0.38). Color version available in the online PDF.

pose tissue, plays a key role in glucose and lipid metabolism (Kadowaki and Yamauchi, 2005). Paradoxically, despite being produced in adipose tissue, adiponectin is negatively correlated with body fatness in humans (Kadowaki and Yamauchi, 2005; Ahima, 2006). In dairy cows, however, a previous study did not detect a relationship between plasma adiponectin concentrations and BCS (Raddatz et al., 2008). Interestingly, we found a negative correlation $\left(P=0.02, \mathrm{R}^{2}=0.16\right.$, data not shown) between plasma adiponectin protein abundance and BCS, which agrees with the human data mentioned above. Here, we did not find effects of $\mathrm{CrPr}$ or RPLM on adiponectin protein abundance.

Taken together, our results indicate that supplemental $\mathrm{CrPr}(8 \mathrm{mg} / \mathrm{d}$ of $\mathrm{Cr}), \mathrm{RPLM}(10 \mathrm{~g} / \mathrm{d}$ of Lys and 5 $\mathrm{g} / \mathrm{d}$ of Met), or both provided for $35 \mathrm{~d}$ had minimal effects on metabolism and adipocyte size but may modulate neutrophil function in lactating dairy cows. Neutrophil inflammatory responses to pathogen-associated molecules may be enhanced by $\mathrm{CrPr}$ supplementation, and RPLM can also influence these responses in a parity-dependent manner.

\section{ACKNOWLEDGMENTS}

We thank Kemin Industries (Des Moines, IA) for providing funding to support this study. We thank Sara Stoakes, Marilyn Diemer, Isabelle Withrock, Morgan Adams, Andrea Jeffery, Sydney Danner, Matthew Avritt, and Michael Scheffel at the Kansas State University (Manhattan) for animal care and technical assistance.

\section{REFERENCES}

Ahima, R. S. 2006. Metabolic actions of adipocyte hormones: Focus on adiponectin. Obesity (Silver Spring) 14(Suppl. 1):9S-15S.

Akter, S. H., S. Häussler, S. Dänicke, U. Müller, D. Von Soosten, J. Rehage, and H. Sauerwein. 2011. Physiological and conjugated linoleic acid-induced changes of adipocyte size in different fat depots of dairy cows during early lactation. J. Dairy Sci. 94:2871-2882.

Bauman, D. E., L. H. Baumgard, B. A. Corl, and J. M. Griinari. 2000 Biosynthesis of conjugated linoleic acid in ruminants. J. Anim. Sci. $77: 1-15$.

Baumgard, L. H., B. A. Corl, D. A. Dwyer, and D. E. Bauman. 2002 Effects of conjugated linoleic acids (CLA) on tissue response to homeostatic signals and plasma variables associated with lipid metabolism in lactating dairy cows. J. Anim. Sci. 80:1285-1293.

Bell, A. W., and D. E. Bauman. 1997. Adaptations of glucose metabolism during pregnancy and lactation. J. Mammary Gland Biol. Neoplasia 2:265-278.

Berthiaume, R., M. C. Thivierge, R. A. Patton, P. Dubreull, M. Stevenson, B. W. McBride, and H. Lapierre. 2006. Effect of ruminally protected methionine on splanchnic metabolism of amino acids in lactating dairy cows. J. Dairy Sci. 89:1621-1634.

Besong, S. A. 1996. Influence of supplemental chromium picolinate on the concentrations of hepatic triglyceride and blood metabolites in dairy cattle. PhD Diss. University of Kentucky, Lexington.

Block, S. S., J. M. Smith, R. A. Ehrhardt, M. C. Diaz, R. P. Rhoads, M. E. Van Amburgh, and Y. R. Boisclair. 2003. Nutritional and developmental regulation of plasma leptin in dairy cattle. J. Dairy Sci. 86:3206-3214.

Blum, J. W., R. M. Bruckmaier, and F. Jans. 1999. Rumen-protected methionine fed to dairy cows: bioavailability and effects on plasma amino acid pattern and plasma metabolite and insulin concentrations. J. Dairy Sci. 82:1991-1998.

Bryan, M. A., M. T. Socha, and D. J. Tomlinson. 2004. Supplementing intensively grazed late-gestation and early-lactation dairy cattle with chromium. J. Dairy Sci. 87:4269-4277.

Bunting, L. D., J. M. Fernandez, D. L. Thompson Jr., and L. L. Southern. 1994. Influence of chromium picolinate on glucose usage and metabolic criteria in growing Holstein calves. J. Anim. Sci. 72:1591-1599

Burton, J. L. 1995. Supplemental chromium: Its benefits to the bovine immune system. Anim. Feed Sci. Technol. 53:117-133.

Burton, J. L., and R. J. Erskine. 2003. Immunity and mastitis. Some new ideas for an old disease. Vet. Clin. North Am. Food Anim. Pract. 19:1-45.

Burton, J. L., B. A. Mallard, and D. N. Mowat. 1993. Effects of supplemental chromium on immune responses of periparturient and early lactation dairy cows. J. Anim. Sci. 71:1532-1539.

Burton, J. L., B. J. Nonnecke, P. L. Dubeski, T. H. Elsasser, and B. A. Mallard. 1996. Effects of supplemental chromium on production of cytokines by mitogen-stimulated bovine peripheral blood mononuclear cells. J. Dairy Sci. 79:2237-2246.

Cefalu, W. T., J. Rood, P. Pinsonat, J. Qin, O. Sereda, L. Levitan, R. A. Anderson, X. H. Zhang, J. M. Martin, C. K. Martin, Z. Q. Wang, and B. Newcomer. 2010. Characterization of the metabolic and physiologic response to chromium supplementation in subjects with type 2 diabetes mellitus. Metabolism 59:755-762.

Chen, G., P. Liu, G. R. Pattar, L. Tackett, P. Bhonagiri, A. B. Strawbridge, and J. S. Elmendorf. 2006. Chromium activates glucose transporter 4 trafficking and enhances insulin-stimulated glucose transport in 3T3-L1 adipocytes via a cholesterol-dependent mechanism. Mol. Endocrinol. 20:857-870.

Chilliard, Y., and M. Doreau. 1997. Influence of supplementary fish oil and rumen-protected methionine on milk yield and composition in dairy cows. J. Dairy Res. 64:173-179.

Cruz, G. D., A. B. Strathe, H. A. Rossow, and J. G. Fadel. 2012. Characterizing bovine adipocyte distribution and its relationship with carcass and meat characteristics using a finite mixture model. J. Anim. Sci. 90:2995-3002.

Floyd, J. C. Jr., S. S. Fajans, J. W. Conn, R. F. Knopf, and J. Rull. 1966. Stimulation of insulin secretion by amino acids. J. Clin. Invest. 45:1487-1502. 
Hayirli, A., D. R. Bremmer, S. J. Bertics, M. T. Socha, and R. R. Grummer. 2001. Effect of chromium supplementation on production and metabolic parameters in periparturient dairy cows. J. Dairy Sci. 84:1218-1230.

Holtenius, P., and K. Holtenius. 2007. A model to estimate insulin sensitivity in dairy cows. Acta Vet. Scand. 49:29.

Ingvartsen, K. L., and Y. R. Boisclair. 2001. Leptin and the regulation of food intake, energy homeostasis and immunity with special focus on periparturient ruminants. Domest. Anim. Endocrinol. $21: 215-250$.

JAMA (Journal of the American Medical Association). 2001. Système international (SI) conversion factors for selected laboratory components. Accessed Aug. 14, 2013. http://www.oup.com/us/ pdf/9780195176339/table_2.pdf.

Kadowaki, T., and T. Yamauchi. 2005. Adiponectin and adiponectin receptors. Endocr. Rev. 26:439-451.

Kehrli, M. E., Jr., B. J. Nonnecke, and J. A. Roth. 1989. Alterations in bovine neutrophil function during the periparturient period. Am. J. Vet. Res. 50:207-214.

Kim, C. W., B. T. Kim, K. H. Park, K. M. Kim, D. J. Lee, S. W. Yang, and N. S. Joo. 2011. Effects of short-term chromium supplementation on insulin sensitivity and body composition in overweight children: Randomized, double-blind, placebo-controlled study. J. Nutr. Biochem. 22:1030-1034.

Kokkonen, T., J. Taponen, T. Anttila, L. Syrjälä-Qvist, C. Delavaud, Y. Chilliard, M. Tuori, and A. T. Tesfa. 2005. Effect of body fatness and glucogenic supplement on lipid and protein mobilization and plasma leptin in dairy cows. J. Dairy Sci. 88:1127-1141.

Konashi, S., K. Takahashi, and Y. Akiba. 2000. Effects of dietary essential amino acid deficiencies on immunological variables in broiler chickens. Br. J. Nutr. 83:449-456.

Leonardi, C., M. Stevenson, and L. E. Armentano. 2003. Effect of two levels of crude protein and methionine supplementation on performance of dairy cows. J. Dairy Sci. 86:4033-4042.

Li, P., Y. L. Yin, D. Li, S. W. Kim, and G. Wu. 2007. Amino acids and immune function. Br. J. Nutr. 98:237-252

Mamedova, L. K., K. Robbins, B. J. Johnson, and B. J. Bradford. 2010. Tissue expression of angiopoietin-like protein 4 in cattle. J. Anim. Sci. 88:124-130.

Mani, V., T. E. Weber, L. H. Baumgard, and N. K. Gabler. 2012 Growth and Development Symposium: Endotoxin, inflammation, and intestinal function in livestock. J. Anim. Sci. 90:1452-1465.

McNamara, J. P. 1991. Regulation of adipose tissue metabolism in support of lactation. J. Dairy Sci. 74:706-719.

McNamara, J. P., and F. Valdez. 2005. Adipose tissue metabolism and production responses to calcium propionate and chromium propionate. J. Dairy Sci. 88:2498-2507.

NRC. 2011. Nutrient Requirements of Dairy Cattle. 7th rev. ed. Natl. Acad. Press, Washington, DC.

Patton, R. A. 2010. Effect of rumen-protected methionine on feed intake, milk production, true milk protein concentration, and true milk protein yield, and the factors that influence these effects: A meta-analysis. J. Dairy Sci. 93:2105-2118.
Raddatz, J. R., A. N. Elias, and C. S. Whisnant. 2008. Measurements of adiponectin in lactating dairy cows. J. Anim. Sci. 86(E-Suppl. 2):60. (Abstr.)

Reist, M., D. Erdin, D. Von Euw, K. Tschuemperlin, H. Leuenberger, C. Delavaud, Y. Chilliard, H. M. Hammon, N. Kuenzi, and J. W. Blum. 2003. Concentrate feeding strategy in lactating dairy cows: Metabolic and endocrine changes with emphasis on leptin. J. Dairy Sci. 86:1690-1706.

Sano, H., S. Narahara, T. Kondo, A. Takahashi, and Y. Terashima. 1993. Insulin responsiveness to glucose and tissue responsiveness to insulin during lactation in dairy cows. Domest. Anim. Endocrinol. 10:191-197.

Smith, K. L., M. R. Waldron, J. K. Drackley, M. T. Socha, and T. R. Overton. 2005. Performance of dairy cows as affected by prepartum dietary carbohydrate source and supplementation with chromium throughout the transition period. J. Dairy Sci. 88:255-263.

Smith, K. L., M. R. Waldron, J. K. Drackley, M. T. Socha, and T. R. Overton. 2008. Metabolism of dairy cows as affected by prepartum dietary carbohydrate source and supplementation with chromium throughout the periparturient period. J. Dairy Sci. 91:2011-2020.

Smith, T. R., and J. P. McNamara. 1990. Regulation of bovine adipose tissue metabolism during lactation 6. Cellularity and hormone sensitive lipase activity as affected by genetic merit and energy intake. J. Dairy Sci. 73:772-783.

Sohn, E. J., M. J. Paape, E. E. Connor, D. D. Bannerman, R. H. Fetterer, and R. R. Peters. 2007. Bacterial lipopolysaccharide stimulates bovine neutrophil production of TNF-alpha, IL-1beta, IL-12 and IFN-gamma. Vet. Res. 38:809-818.

Spears, J. W., C. S. Whisnant, G. B. Huntington, K. E. Lloyd, R. S. Fry, K. Krafka, A. Lamptey, and J. Hyda. 2012. Chromium propionate enhances insulin sensitivity in growing cattle. J. Dairy Sci. 95:2037-2045

Subiyatno, A., D. N. Mowat, and W. Z. Yang. 1996. Metabolite and hormonal responses to glucose or propionate infusions in periparturient dairy cows supplemented with chromium. J. Dairy Sci. 79:1436-1445

Sumner, J. M., F. Valdez, and J. P. McNamara. 2007. Effects of chromium propionate on response to an intravenous glucose tolerance test in growing Holstein heifers. J. Dairy Sci. 90:3467-3474.

Vargas-Rodriguez, C. F., K. Yuan, E. C. Titgemeyer, L. K. Mamedova, K. E. Griswold, and B. J. Bradford. 2014. Effects of supplemental chromium propionate and amino acids on productivity, diet digestibility, and energy balance of peak-lactation dairy cattle. J. Dairy Sci. 97:3815-3821. 10.3168/jds.2013-7767.

Wang, Z. Q., and W. T. Cefalu. 2010. Current concepts about chromium supplementation in type 2 diabetes and insulin resistance. Curr. Diab. Rep. 10:145-151.

Yuan, K., R. D. Shaver, S. J. Bertics, M. Espineira, and R. R. Grummer. 2012. Effect of rumen-protected niacin on lipid metabolism, oxidative stress, and performance of transition dairy cows. J. Dairy Sci. 95:2673-2679. 